\title{
Teachers' Opinion Regarding Teacher Evaluation in Undergraduate Medical Education
}

\author{
Nahid Shahana', Prof. Dr. Iffat Ara', Prof. Dr. Humayun Kabir Talukder ${ }^{3}$, Dr. Farhana Hussain ${ }^{4}$, Dr. Farhana Alamgir \\ Moony, Polly Zinnat Ara ${ }^{6}$
}

\begin{abstract}
IThis descriptive type of cross-sectional study was conducted to find out the teachers' opinion about teacher evaluation in undergraduate medical education at two government and three non-government medical colleges in Dhaka city by convenience sampling. 30 teachers were participated and they were from Assistant Professor to Professor Level. Teachers gave their opinion about potential use, facilities, barriers and factors affecting the implementation of teacher evaluation through in-depth interview.

Majority of teachers opined that a well developed teacher evaluation system is a must in undergraduate medical education. It is strongly felt by the participant teachers that teacher evaluation has presently become very much essential against the backdrop of continuous changing of curriculum, technology, teaching styles, pattern of society, disease demography etc. Teachers agreed that it can improve teaching ability and protect students from incompetent teachers. Most of the teachers agreed about the necessity of student involvement in the teacher evaluation programme. Problem if arise can be resolved by implementing teacher evaluation with the help of a precise or proper guideline from policy level.
\end{abstract}

Study recommended that teacher evaluation should start from undergraduate medical college. Study also mentioned that teachers' classroom performance and relationship with students should be used as parameters of teacher evaluation.

In conclusion it can be said that without teacher evaluation there is no way for quality improvement of teacher and undergraduate medical education.

Key Words: Teacher evaluation, medical teacher, classroom performance

\section{Introduction}

Evaluation is an integral part of medical education. The aim of the study is to elicit teachers and students view on the teacher evaluation of medical education. ${ }^{1-3}$ No denying the fact that medical education system of a country has got very important role in contributing towards improvement of health sector. With rapid change of science and technology, time has come for medical education to fit in with the changing scenario. ${ }^{2}$

Medical teachers are strong stakeholders of the entire medical education system. Conventional role of the medical teachers as 'information provider' has undergone immense change in recent times and now they have to play multiple roles such as: facilitator, curriculum and course planner, resource material creator, student assessor, mentor and program evaluator etc.

\footnotetext{
${ }^{1}$ Assoc. Prof., Dept. of Anatomy, Bangladesh Medical College ${ }^{2}$ Prof. \& Head, Dept of Gynae \& Obs, Dhaka Medical College ${ }^{3}$ Professo, Curriculum Development \& Evaluation, CME, Dhaka ${ }^{4}$ Asst. Prof. Dept of Anatomy, Bangladesh Medical College ${ }^{5}$ Assoc. Prof. Dept of Microbiology, Bangladesh Medical College ${ }^{6}$ Assoc. Prof., Dept of Physiology, Ibrahim Medical College
}

Address of correspondence: Nahid Shahana.

Assoc. Prof., Dept. of Anatomy, Bangladesh Medical College

Email: n.shahana@yahoo.com
Teacher evaluation can be a positive experience for the both teachers and students. It is a series of activities and actions that are interconnected and relate to a specific purpose. The general purpose of teacher evaluation is to safeguard and improve the quality of instruction received by students. ${ }^{2-6}$

Personnel decisions such as retention, transfer, tenure, promotion, demotion, and dismissal can be applied through an effective evaluation process. Teacher evaluation is capable of protecting students from incompetent teachers. It should strive to improve instruction by fostering selfdevelopment of the teachers. ${ }^{2,3}$ The real challenge for effective teacher evaluation is to understand teaching as collective practice where teachers do not work alone but with a system that provides the framework in which they can think and act. ${ }^{3,4}$

By sharing professional knowledge and practices, teachers can become enlightened and gather a deeper understanding of what constitutes effective teaching. Teachers are capable of identifying directions for self-improvement and carrying out plans to improve their effectiveness. Being a professional teacher implies a moral commitment to exemplary practice which results in high levels of student learning .Clearly, an aim of evaluation should be to enable teachers to analyze their own teaching to identify genuine needs and interests. ${ }^{3-6}$

Teachers should be provided with a problem solving

Bangladesh Journal of Medical Education 2015;6(1):12-18. C 2015 Shahana et al., publisher and licensee Association for Medical Education. This is an Open Access article which permits unrestricted non-commercial use, provided the original work is properly cited. 
orientation. So that they can become teacher-learners rather than masters of a repertoire of skills. How teachers see them as teachers and how this is evaluated is a result of circumstances and experiences. Therefore, evaluation can only be viewed and interpreted under those conditions. Any teacher evaluation should be dependent upon teachers continually questioning and reinterpreting what constitutes effective teaching. The changing context of teaching and the dynamic needs of students are continual factors in this process. $^{5,6}$

A common belief shared among educators, policymakers, curriculum developers, and administrators is that high quality education is virtually unattainable without high quality teaching staff. Thus, a fundamental requirement for all academic institutions is to attract and retain high quality teachers. ${ }^{4}$

Standard of medical education depends upon quality working force which depends on quality education. Medical teaching desires an expert teaching faculty more than any other education. It is observed there is hardly a systemic teacher evaluation program. Most of the programa available are aimed at the development of technical and clinical skills rather than improving teaching skill. There is neither any infrastructure nor any arrangement for systemic program in any level.

Aquario stated that the importance of students' participation in the teacher evaluation process has been recognized by Ministers of the participating countries in the Bologna Process since the Prague Declaration (2001), which states that "students are the full member of the higher education community", and that therefore they "should participate in and influence the organization and content of education at Universities". Teacher evaluation by peers and teacher themselves are popular and common.

The system of teaching evaluation contributed to the perceived improvement of teaching quality and faculty's teaching skills at SMMU (Second Military Medical University, Shanghai, and People's Republic of China). ${ }^{6}$

\section{Methodology}

The study was a cross-sectional descriptive study. The study was conducted at two government and three nongovernment medical colleges in Dhaka city by convenience sampling. This study was done during the period between July 2013 to June 2014involving 30 medical teachers from Assistant Professor to Professor Level of different discipline. The teachers who were present and willing to participate were to include in this study. For the collection of information (data) an interview schedule was developed as guideline for in-depth interview of teacher. The research instrument was developed in English and pretested before finalization. Opinion of 30 teachers was collected through in-depth interview. All the data were checked, edited and arranged manually and subsequently an interpretation was made. Then the data was presented in narrative form. To collect the necessary information and data, due permission from colleges, departments and teachers were taken, mentioning purpose of the study. No identity of the participating teachers was disclosed to ensure confidentiality.

\section{Result}

The teachers' opinions regarding teacher evaluation were taken through in-depth interview of teachers of selected medical colleges. The questions were open according to the variables. Probing and follow-up questions were asked according to answers. In-depth interview was taken from 30 teacher respondents among professors, associate professors and assistant professors. Eleven teachers from selected government medical colleges and nineteen teachers from selected non-government medical colleges were participated in this interview. Among them 10 were professors, 13 associate professors and 7 assistant professors. The teacher respondents were 14 from preclinical, 11 from para clinical and 5 from clinical departments.

The following are the opinions of the teacher respondents regarding the questions asked

\section{1. "Please express your idea about teacher evaluation".}

All teacher respondents had some idea about teacher evaluation. Some of them mentioned that private universities have started teacher evaluation in their institutions. But in medical and dental colleges both government and non-government it is yet to be started.

During interview majority of the teachers told that there should be a well organized teacher evaluation programme for medical teachers and some teachers told that they had no clear cut idea about teacher evaluation. They expressed their opinion about the areas to be developed for medical teachers which are as follow: professional skill on teaching, assessment, depth of knowledge on own subject, friendly environment with the students, IT knowledge and managerial skill. Some other teacher respondents added their idea about teacher evaluation as given below:

"Now a days teacher evaluation is essential for medical education".

"If teacher evaluation is properly implemented then all medical colleges will run in systematic way". "Teacher evaluation is very much essential and it will ensure quality of teaching".

"Teacher evaluation is necessary but it is very difficult to implement in our context".

\section{2. "Explain the necessity of teacher evaluation"}

All teachers agreed about the necessity of teacher evaluation in medical education. 
One Professor said that, "Medical education is not that much modernized, teacher's evaluation will enhance the standard of medical education". Another Professor commented that, "Healthy, standard and up-grade academic activities can be maintained by teacher evaluation. So, there is no way other than teacher evaluation". A group of teachers said that, "Teaching experience should be the main criteria for teacher evaluation".

One of the Assistant Professors noted that, "For better performance teacher evaluation is very much essential, the whole education system should be brought under this". One of the teachers made comment that, "If teacher evaluation starts in our institution then educational environment will change. Not only medical colleges, teacher evaluation are needed in every educational system".

A group of teachers said that, "In case of the non-government medical colleges, sometimes teacher recruitment is done by spoil system. If teacher evaluation system is introduces this will help screening out unfit teachers".

3. "What are the facilities that exist in your medical colleges for teacher evaluation".

All teachers agreed that all facilities are available in their medical colleges but $75 \%$ teachers think that the teacher evaluation activities in their medical college are not yet very effective, $20 \%$ teachers think that it is effective to some extent and 5\% think that it is not effective at all. One senior Professor said that, "Departmental Head takes continuous evaluation of the teacher without proper documentation".

4. "What are the factors affecting teacher evaluation --in your opinion".

According to the opinion of the teacher respondents the factors affecting the teacher evaluation are: lack of proper guide line at the policy level $(80 \%)$, teachers' involvement in politics $(75 \%)$, lack of initiative by the government $(60 \%)$, lack of awareness of the college authority $(45 \%)$ and lack of self-interest (15\%).

\section{5. "What are the barriers in implementing teacher} evaluation".

According to the opinion of the teacher respondents the barriers to implement teacher evaluation are: teachers are less motivated $(80 \%)$, requires trained evaluators $(75 \%)$, time constraint $(60 \%)$, monitoring problem $(50 \%)$. One of the Professors said that, "It is not possible without maintaining confidentiality".

6. "What may be the potential use of teacher evaluation in your medical college".

Most of the teachers proposed teacher evaluation as a potential tool for assessing teaching ability. Maximum teachers agreed that teacher evaluation can protect students from incompetent teacher. Some of them also gave opinion, "If teacher evaluation starts then teachers are under observation of the authority with regard to their performance". Roughly $80 \%$ teachers said that, "Teacher evaluation system can improve teaching quality of the teacher and also improve learning outcomes of the students".

7. "What might be the areas potential with misuse of teacher evaluation".

In relation to the misuse of teacher evaluation a great number of teacher respondents expressed that political interference may hamper teacher evaluation program. $80 \%$ teachers said unfairness may hamper implementing teacher evaluation process. $100 \%$ teachers agreed that teachers may try to satisfy the evaluator rather than concentrating on teaching. Another teacher said that, "Teachers' evaluation will be misused if the administrator is politically biased".

\section{8. "What parameters can be used for teacher evaluation"}

When asked question about the tools for teacher evaluation, every teacher gave importance to the teachers classroom performance. Six professors commented that students' assessment results should also be used as parameters. One of the Associate Professors said that, "Teachers' performance, honesty, punctuality are the parameters for the teacher evaluation". They want to see that the Principal/Head of the department should act as a role-model in this regard. Some of the teachers' opined that, "Higher degree and previous work experience is a must for teacher evaluation".

9. "Who can take the responsibility to implement teacher evaluation programme in your medical college". Most of the teachers said that the evaluator should be an expert. Eight professors said that Principal could be an evaluator. One Assistant Professor said that, "Departmental head can evaluate them". Another Associate Professor gave her comment that, "For the lecturers or junior teachers departmental head is the best evaluator". Most of the teachers gave opinion that responsible authority for teacher evaluation should the Directorate General of Health Service. Some of them also said that Governing Body of the institutes can do it. One Professor said that, "Ministry of Health and Family Welfare may be the central authority of medical teacher evaluation".

10."Are you in favor of implementing teacher evaluation in your medical college".

Most of the teachers want to start teacher evaluation in their colleges. Only one teacher is against this opinion. He said that, "It should be implemented in every educational institute prior to implementing in Medical Colleges". One Professor said that, "It is difficult to implement teacher evaluation in private medical colleges".

\section{1. "As a teacher would you like to be evaluated".}

Most of the teachers strongly agreed to this question. They want to get their job satisfaction and proper appreciation through teacher evaluation. Some of the teachers disagreed also.

12. "What is your opinion about involving students in teacher evaluation".

About $90 \%$ of the teacher respondents gave opinion that

Bangladesh Journal of Medical Education 2015;6(1):12-18. 
students are the best evaluators for the teacher. $10 \%$ of the teacher respondents negatively opined about it. The teacher respondents gave some suggestions for improving medical education situation in Bangladesh which are: Proper guide line at the policy level, increase of teacher training program, increase of CME/CPD activity, impartial judgment and provision for registration subject to fulfillment of some definite criteria.

\section{Discussion}

This study is carried out among the teachers of two government and three non-government medical colleges of Dhaka city. Teachers of the selected medical colleges were considered as respondents. They were from Assistant professor to Professor covering all disciplines of the selected medical colleges. Questionnaires for teachers were prepared to get opinion regarding teacher evaluation in undergraduate medical education. In response, 30 teachers gave their opinion through in-depth interview. Among the teacher respondents of in-depth interview, out of 30 teachers 13 (43.3\%) were Associate Professors, 10 (33.3\%) were Professors and 7 (23.4\%) were Assistant Professors.

Regarding teacher evaluation, most of the teacher respondents said that it is necessary for medical education. Only a few teachers were confused at first time. After explaining some pros and cons of teacher evaluation, then most of them agreed about the necessity of teacher evaluation. Therefore, it was concluded that teacher evaluation is a necessity and will ultimately change the educational environment of the undergraduate medical education.

Marshall believes that evaluation facilitates teacher's growth if it is based on multiple sources of data; includes clear, relevant, and meaningful performance criteria; focuses on peer assistance and teachers' goal setting; fosters mutual trust between the teacher and evaluator.

More importance should be given to the perceptions of students to improve the educational environment, as perceptions are associated positively with learning outcome, learning approach and attitude toward studying. Use of the DREEM (Dundee Ready Educational Environment Measure) as a monitoring tool might permit timely interventions to remediate problematic educational environments. ${ }^{68}$,

Danielson discussed that the push for teacher quality has developed from the modern school reform movement. The movement's first phase began with the 1983 publication of $A$ Nation at Risk (National Commission on Excellence in Education) and concentrated on such issues as lengthening the school year and requiring more academic courses. The second phase, which began in the 1990s and continues to this day, has focused on the role of challenging academic standards for students and the use of high-stakes assessments of those standards. The third phase dates from the 1996 publication of What Matters Most: Teaching for
America's Future (National Commission on Teaching and America's Future) and has propelled the concept of teacher quality to the forefront of the policy agenda. ${ }^{8}$

Finding regarding 'the potential use of teacher evaluation, by teacher respondents through in-depth interview. Maximum teachers concluded that about potential use of teacher evaluation it will be helpful to improve teaching quality and also improve learning outcomes of the students. Some of them also mentioned that it should be used for promotion. Some of the teacher mentioned that if evaluation starts properly then job satisfaction will be enhanced. Job satisfaction is important part for better output of the teachers' capability. The potential power of the research on learning was a major force behind the development of the Dimensions of Learning model. ${ }^{8-10}$ Dimensions are five types of thinking: positive attitudes and perceptions about learning; ways of acquiring and integrating knowledge; extending and refining knowledge; using knowledge meaningfully; and developing productive habits of mind, including critical, creative, and self-regulated thinking and learning. ${ }^{10}$

The finding regarding "the potential misuse of teacher evaluation" is that all the teacher respondents agreed on the fact that it may create unhealthy competition among teachers. It may hamper friendly environment in the medical colleges. A great number of teachers expressed that political interference may hamper teacher evaluation programme. $80 \%$ teachers said unfairness may hamper implementing teacher evaluation process. $90 \%$ teachers agreed that teachers may try to satisfy the evaluator rather than concentrating on their teaching. Some teachers mentioned that if examination results are used as yardstick of teacher evaluation, there will be a tendency to make the students early pass rather than ensuring their deep learning. In every work there are some drawbacks. Teacher evaluation is no exception. Over the time it could be corrected and the evaluation process will be more effective gradually. In the first world countries previously it was a problem but at present they have overcome by improving the evaluation system like peer evaluation which consists of two colleagues (teachers) with comparable educational background evaluating each other. In case of our country, it is possible to overcome by giving proper guideline and making authority responsible to ensure its effective application. Here members of the evaluation committee should be medical educationist.

Respondents by their opinion regarding implementation of teacher evaluation in their medical colleges overwhelmingly wanted to implement teacher evaluation in their medical colleges. Only one teacher differed. Majority opined that if teacher evaluation is introduced, then teaching environment will be changed and teachers will be benefited. The professor who differed mentioned that it is very difficult to implement. But he did not deny that teacher evaluation system for improvement of medical education is a necessity and should be started immediately.

Bangladesh Journal of Medical Education 2015;6(1):12-18. 
Respondents by their opinion regarding "facilities that exist in their medical colleges for teacher evaluation. Almost every teacher gave opinion that principal, vice principal may be evaluators and results of the students can be the parameters for teacher evaluation. Some of teacher respondents gave opinion that departmental heads may be the evaluator for departmental teachers. Only a half of the teachers agreed that students are good evaluator of their teachers. Principals are the academic head of the medical colleges and it is his/ her prior duty to make sure that the evaluation system is introduced.

Respondents by their opinion regarding "the barriers to implement teacher evaluation in their medical colleges", most of the teacher respondents gave opinion that teachers are less motivated (80\%), $75 \%$ teachers mentioned that it requires trained evaluators and there is time constraint and monitoring problem. Some teachers also gave opinion that political influence and personal relationship may hamper it. Some teachers also mentioned that if proper criteria are given for the teacher evaluation then it can be implemented easily. Mukhtar and Chaudhry mentioned in his article that the medical schools in Pakistan identified lack of incentives $20(54 \%)$, lack of faculty interest $15(40 \%)$ and a shortage of trained facilitators $15(40 \%)$ as barriers to faculty development activities. According to a study conducted in the medical schools of Canada, the main obstacles to faculty development programs identified were lack of funds, poor participation and lack of evaluation facilitator. ${ }^{11,14}$ In another study conducted by Smolen on nurses, the factors affecting faculty development were identified as the non-availability of resources, lack of faculty interest and faculty responsibility for professional development. The non availability of full time faculty, constraints of time and money and lack of infrastructure were the barriers identified in medical colleges of India.

Regarding factors that may "affect the teacher evaluation program" according to the opinion of the teacher respondents through in-depth interview the factors affecting the teacher evaluation, $80 \%$ teachers think of lack of proper guideline at the policy level, $75 \%$ teachers' think of involvement in national politics, $60 \%$ lack of initiative by the government, $45 \%$ lack of awareness of college authority and $15 \%$ lack of self interest. Present study can be compared with Srinivas and Adkoli's report, where it is said that faculty development is constrained by lack of commitment at various level ----Central and State government, regulatory bodies, college management and teachers. Financial grant was also low and irregular. There was no recognition or reward from college management for faculty development activities. ${ }^{12}$

Respondents by their opinion regarding "the parameters used for teacher evaluation in their medical colleges" every teacher respondents gave importance of the teachers' classroom performance. Some of the professors mentioned that teachers' performance, honesty, punctuality are the parameters for the teacher evaluation. They want to see that the principal/head of the department should act as a role model in this regard.

Machell suggested in his article that the level of classroom observation was another attribute of evaluation procedures often mentioned by interviewees. According to him, one responding teacher indicated that a well structured procedure consisting of a pre-observation conference stood out as being the most important factor related to the overall quality. Another interviewee stated that the formal observation with a preconference, at which time the evaluator provided the teacher a copy of the observation instrument that addressed the teaching standards, resulted in positive perceptions of the overall quality of the evaluation.

In the Amin investigation, $76 \%$ of the subjects stated that the teacher's communication skills were important for assessment. ${ }^{14}$ Dr. Seif's, study showed that teacher evaluation seemed less likely to be affected by teaching quality and students learning ability, in contrast, it seemed more likely to be changed by the teacher's methods and procedures. The study pointed out that there was $75 \%$ coefficient due to implementing the evaluation from the students' point of view, with regard to the popularity surveys form, allocated to favour teachers and the quality of education. ${ }^{15}$

Considering the question of regarding "students as evaluator", most of the teachers welcomed the student's involvement in teacher evaluation. In case of in-depth interview about $90 \%$ of the teacher respondents gave opinion that students are the best evaluators for the teacher but $10 \%$ of the teachers negatively opined about it. The teacher respondents gave some suggestions for improving medical education situation in Bangladesh which are: proper guide line at the policy level, increase of teacher training program, increase of CME/CPD activity, impartial judgment and provision for registration making conditional to fulfillment of some definite criteria. ${ }^{15}$ Karmar discussed in his article that teacher think that students are not eligible to judge, due to their lack of adequate knowledge about the training process, thus, student's evaluation is not acceptable, and some teachers also believe that student's personal ideas may have biased the assessment process. ${ }^{5}{ }^{15}$ According Dankin opinion, teacher assessment through students is not usually authorized to be a base for decision-making (promotion, eulogy, punishment, or selecting the eligible teacher). Implementing other evaluation methods, especially those that are determinants for learning ability (learning rate) and following the teachers' teaching and education seems beneficial. Singapore Universities experience that the terms of designing a new evaluation method based on ability, for determining the minimum and maximum ability of a teacher can be useful. ${ }^{15}$

Considering the question about "who should take the initiative for teacher evaluation program" most of the teachers said that the evaluator should be an expert and they mentioned that head of the institutes such as principal/vice principal could be an evaluator who closely follows the

Bangladesh Journal of Medical Education 2015;6(1):12-18. 
teachers. A small number of teachers mentioned about an evaluation committee which may be formed by academic council. Some of the teachers are not interested to be evaluated by the students and peers. But a large number of teachers are agreeing about self evaluation. Medical Education Units can play a critical role in faculty development and thus contribute to educational improvement and reforms in a major way. ${ }^{16-18}$ There is an urgent need for educational leaders to come forward with strategies to overcome this crisis in medical education and initiate reforms at the earliest.

Considering the question about "as a teacher would you like to be evaluated" most of the teachers strongly agreed to this question. They want to get their job satisfaction and proper appreciation through teacher evaluation on condition of confidentiality.

To improve the assessment of teaching effectiveness, the use of a triangulation model is suggested, whereby evaluation methods from all three categories of students, peers, and self are performed routinely. ${ }^{1,3,17}$

Student evaluations are valuable when related to course organization and instructor delivery, but not when students are asked to evaluate course content, relevancy, or appropriateness of goals and objectives. Many dental schools, however, value student views regarding curriculum. ${ }^{17}$

The process by which most teachers are supervised and evaluated is inefficient, ineffective, and a poor use of principals' time, argues Mr. Marshall. It needs to be drastically streamlined and linked to a broader strategy for improving teaching and learning (Marshall). Weiss mentioned that the next generation of evaluation systems will further integrate teacher accountability with professional growth. ${ }^{18}$ Eisner conceives of evaluation as inherently part of teachers' everyday work life. Evaluation needs to be participatory and reflective in order to be meaningful for teachers. Reform of teacher evaluation systems is already supporting the success of broader school reform efforts, which include the requirements of teachers' evolving roles the goal of these changes being meaningful learning experiences for our children. ${ }^{6,19}$.

Brandt expressed in his study that not every teacher is changing, of course, but even very traditional teachers are doing traditional teaching better, because they recognize the need for more active student involvement, more imaginative approaches to assessment. Real change is happening in the schools --- and the new approaches to teacher evaluation are a natural part of it. ${ }^{3,20}$

According to the students' evaluation, and for importance in terms of increase in the quality and improvement in the education process in universities, we propose that attuned comprehensive planning, with elite teachers and students from all universities, come together and design a teacher evaluation form, and alternative methods be executed till functional evaluation of the teacher educational practice is facilitated. ${ }^{15-19}$

\section{References}

1. Schiekirka S, Reinhardt D, Heim S, Fabry G, Pukrop T, Anders $\mathrm{S}$ et al. 2 Students perceptions of evaluation in undergraduate medical education: A qualitative study from one medical school. BMC Medical Education 2012;22: pp 1-2.

2. Sawa R. Teacher evaluation policies and practice. Thesis 1995; (SSTA Research centre report).

3. Ellefson L. Collaborative policy development in teacher evaluation. Thesis (Master of education) 1997; University of Lethbridge.

4. Olah DA. A study of North Carolina technology evaluation practices and job satisfaction. Dissertation (PhD) 2013; name of the university.

5. Aquario D. The active participation of students in teaching evaluation processes within universities. Thesis (PhD) 2012; University of Padova Italy.

6. Wen SH, Xu J S, Carline JD, Zhong F, Zhong Y J, Shen $\mathrm{S}$ J. Effects of a teaching evaluation system: a case study. International Journal of Medical Education 2011; 2: pp18-23.

7. Namaghi SAO. A data-driven conceptualization of teacher evaluation. The Qualitative Report 2010; $15(6): \mathrm{pp} 15041522$. Retrieved from http://www.nova.edu/s s / QR/QR 156/0stovarnamaghi.pdf

8. Mayya S, Roff S. Students' perceptions of the educational environment: a comparison of academic achievers and underachievers at Kasturba Medical College, India. Educ. Health2004; 17(3): pp 208-291.

9. Danielson C. New trends in teacher evaluation. The Leadership Academy Developer2001; 1(3): pp 1-3.

10. Marzano RJ, Pickering DJ, Arredondo D E, Blackburn G B, Brandt RS, and Moffett C A. Dimensions of Learning, Teacher's Manual 1992;. Alexandria, Va: Association for Supervision and Curriculum Development.

11. Arrendondo D, Lechner Brody J, Power Zimmerman D, Moffett C. Pushing the envelope in supervision. Educational Leadership 1995; 53(3): pp 74-78.

12. Mukhter F, Chaudhry AM. Faculty development in medical institutions: where do we stand in Pakistan? Journal of Ayub Med Coll Abbottabad 2010; 22(3): pp 210-213. Retrieved from http://www.ayubmed.edu.pk/ JAMCP/PAST/22-3/Fatima.pdf

13. Srinivas, D. K., Adkoli, B. V. Faculty development in medical education in India: The need of the day. Al Ameen Journal of Medical Science 2009; 2: pp 6-13. 
14. Machell J. The teacher evaluation instrument: An examination of attributes related to teacher growth. Journal of Personnel Evaluation in Education1995; 9(3): pp259-73.

15. Amin DMS. Views of teachers regarding teachers' evaluation in undergraduate dental education. Thesis (MMEd course) 2011; University of Dhaka.

16. Kamran A, Zibaei M, Mirkaimi K, Shahnazi H. Designing and evaluation of the teaching quality assessment form from the point of view of the Lorestan University of Medical Sciences Students. Journal of Education and Health Promotion 2012; 1; p1.

17. Singh T, Bansal P, Sharma M. A need and necessity for faculty development: the role of medical education unit in the Indian context. South East Asian Journal of Medical Education2008;2:pp 2-6.
18. Jahangiri L, Mucciolo TW, Choi M, Spielmen AI. Assessment of teaching effectiveness in U.S. Dental schools and the value of triangulation. Journal of Dental Education 2008; 1:p 1.

19. Weiss EM. New directions in teacher evaluation.1998. ERIC digest (Ed429052) Retrieved from http://www. Ied.edu.kh/edchange/resource/education4_2-8.html

20. Eisner EW. Educational reform and ecology of schooling. 1992. Teachers college report, 93(4): pp612627.

21. Brandt R. On a new direction for teacher evaluation: A conversation with Tom McGreal. Educational Leadership 1996; 53(6): pp 30-33.

Bangladesh Journal of Medical Education 2015;6(1):12-18. 